\title{
TESTING AND ANALYSIS OF HEMLOCK CROSS LAMINATED TIMBER
}

\author{
Wenbo Xie, Yewei Ding, Zheng Wang, Zizhen Gao, Tongyue Zhang, Yuhao Zhou, \\ Yuhang He, Xiuling Huang \\ Nanjing Forestry University \\ China
}

(RECEIVED JANUARY 2020)

\begin{abstract}
In this paper, the three-layer Canadian hemlock CLT panel was designed to test the elastic modulus and bending strength of CLT specimens by four-point bending method. The interlaminar shear of CLT specimens was tested by short-span three-point bending method. Strength, the shear strength and wood breaking rate of the CLT specimens were tested by the stair shear method. At the same time, the failure mode of the CLT board was analyzed. The main conclusions indicate that the test values of bending and shear performance of Hemlock CLT can meet the relevant grade requirements of standard ANSI APA PRG320: 2012. During the bending process, the CLT specimen firstly exhibits a rolling shear failure of vertical layer after reaching the non-elastic deformation phase. After that, the damage extends gradually to the interface layer. The final failure mode is shear failure of interface layer or tensile failure of parallel layer. The interlaminar shear performance is partly relevant to the converted timber performance of parallel layer of CLT under the short-span three-point bending test conditions. The position of interlaminar shear failures is concentrated near support points of specimens and the position is generally located at the interface between parallel and vertical layers, inclining to the parallel ones. CLT at Grade 1 has significantly higher interlaminar shear strength than CLT at Grade 2. There is a certain variability in the test results of wood failure rate of CLT. The overall mechanical properties of the hemlock specification material and the hemlock CLT can meet the relevant grade requirements of Standard ANSI APA PRG320: 2012. The above can provide reference for the optimization design and application work of CLT heavy-duty timber structure.
\end{abstract}

KEYWORDS: Hemlock, cross-laminated timber, four-point bending, short-span three-point bending, the stair shear method.

\section{INTRODUCTION}

Cross laminated timber (CLT) is a basic unit product used in a new generation of heavy-duty wood structures developed in Germany and Austria. CLT is usually manufactured by factory 
prefabrication, which greatly improves on-site construction efficiency, reduces construction costs, and reduces dust and noise on the construction site. In middle and high-rise buildings, factory prefabrication and simple and quick installation methods greatly shorten the construction time of buildings, which is one of the main advantages of CLT applied in buildings (Wang et al. 2017, Brandner 2018, Follesa and Fragiacomo 2018, Minmin et al. 2018a, Minmin et al. 2018b). CLT buildings also have the advantages of light weight, high strength, good structural integrity, good thermal insulation and durability (Cao et al. 2016, Sikora et al. 2016, Zhou et al. 2016, Lu et al. 2018). Therefore, CLT is regarded as a good choice to increase the added value of forest products. As a new type of wood composite building material, CLT's structural design, processing technology and quality control are particularly important. If the processing technology and parameters of CLT are not well controlled, it will directly lead to the decline of various performance indicators of the CLT products produced. Therefore, before a new tree species is used as the raw material or a new CLT production line is just established, the mechanical properties of the first batch of CLT products designed and manufactured must be tested and evaluated (Luengo et al. 2017, Wang et al. 2018, Sung-Jun and Young 2018, Dugmore et al. 2019, Haitao et al. 2020). The specific evaluation should include whether the performance indicators can meet the needs of engineering applications, in order to provide the necessary theoretical basis for quality control and process improvement in subsequent CLT production (Wang et al. 2014, Wang et al. 2015, Xiaojun et al. 2018, Haitao et al. 2019, Wang et al. 2019, Wenbo et al. 2019).

The three-layer Canadian hemlock CLT plate was designed as the research object. The elastic modulus, flexural strength and shear strength, the shear strength of the rubber layer and the durability of the rubber layer in the main strength direction of the CLT plate were studied. Such test and analysis were carried out in order to provide useful references to optimize the structural design as well as the testing and analytic technics of mechanical properties for full-scale CLT plates.

\section{MATERIAL AND METHODS}

\section{Design and manufacture of three-layer CLT}

The CLT panel used in current work has a three-layer unit structure, each layer has a thickness of $35 \mathrm{~mm}$, and is designed into grades 1 and 2, which are respectively used for the wallboard and floor of the demonstration building.

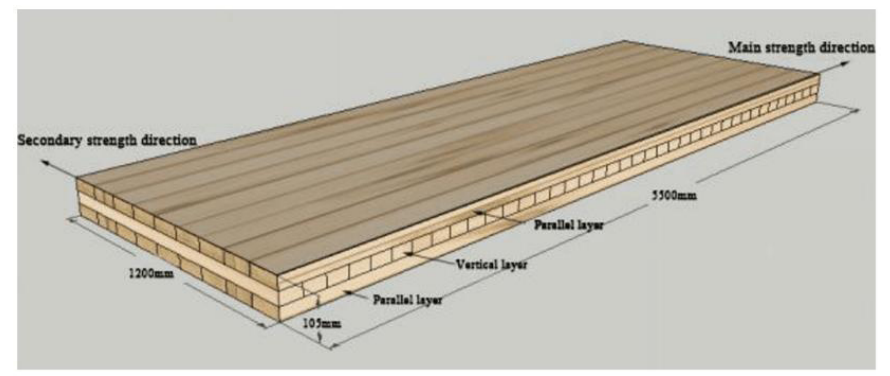

Fig. 1: Three layers CLT structure diagram.

The dimensions of CLT for this test is $5500 \times 1200 \times 105 \mathrm{~mm}$, and its unit structure is shown in Fig. 1. 
The CLT test piece is produced in Ningbo, China according to the Canadian CLT handbook (Gagnon and Bilek 2012) and the Canadian CLT conventional production process. There are two types of CLT manufactured: the parallel layer of which is grade 1 hemlock (elastic modulus 12.8 $\mathrm{GPa}$ ), numbered 1, 2, 3, is named grade 1 hemlock CLT (three layers); the parallel layer of which is grade 2 hemlock (elastic modulus $10.3 \mathrm{GPa}$ ), numbered 4, 6, 8 is named grade 2 hemlock CLT (three layers). The vertical modulus of the grade 1, grade 2 hemlock three-layer CLT board has an average modulus of $7.4 \mathrm{GPa}$.

One-component polyurethane (PUR) is selected as the adhesive. V-shaped leaching process is adopted with the adhesive spread of $180 \mathrm{~g} \cdot \mathrm{m}^{-2}$ and the thickness of hemlock substrate $38 \mathrm{~mm}$. Wood surface can be easily passivated because of exposure in the air for a longtime, which could definitely affect affecting the quality of gluing. Therefore, the wood should be thickened and shaved within 24 hours before the slab is glued. The thickness of the unit should also be controlled at $35 \mathrm{~mm}$. The adhesive is prevented from being exposed in the air for long time by controlling the opening time from the start of gluing to the start of cold pressing within $30 \mathrm{~min}$. In cold compression process, the surface pressure is $1.2 \mathrm{MPa}$; the lateral pressure is $0.3 \mathrm{MPa}$; the cold pressing time is $90 \mathrm{~min}$.

\section{Test material}

In this work, the dimensions of above full-scale CLT slab is $5300 \times 1200 \times 105 \mathrm{~mm}$. According to the North American standard ANSI APA PRG320-2012, these slabs are cut into suitable dimensions for the tests of four-point bending elastic modulus, bending strength, wood failure, impregnation strip ratios, interlayer and adhesive shear strengths (Fig. 2).

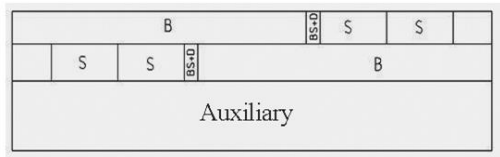

Fig. 2: Specimen cutting diagram.

In Fig. 2, there are two specimens are taken from each CLT for B, a total of 12 specimens, which is a four-point bending test specimen with a dimensions of $3300 \times 305 \mathrm{~mm}$. S is a short beam shear test specimen with dimensions $735 \times 305 \mathrm{~mm}$. There are four specimens for each CLT, a total of 24 specimens. $\mathrm{D}$ is an impregnation peeling specimen, with dimensions $100 \times 100 \mathrm{~mm}$. There are two specimens for each CLT, a total of 12 test pieces. BS is an adhesive shear test specimen, with dimensions $100 \times 100 \mathrm{~mm}$. There are four specimens for each CLT, a total of 24 specimens. Wherein, two specimens are used for adhesive layer shear test in dry state; the other two for adhesive layer shear test in vacuum-pressure state. After sawing, the adhesive layer shear specimen is processed into the stair with the height $6 \mathrm{~mm}$.

\section{Equipment for four-point bending and short beam shear tests of CLT}

The 30T long-span beam testing machine with a set of load-displacement analysis software (produced by Jinan Tianchen Testing Machine Manufacturing Co., Ltd), a displacement extensometer $(0-300 \mathrm{~mm})$; a block of L-shaped steel and a tape measure $(0-10 \mathrm{~m})$.

\section{Equipment for adhesive layer shear test of CLT}

The 10T universal mechanical testing machine consists of a set of load-displacement analysis software (produced by Jinan Tianchen Testing Machine Manufacturing Co., Ltd); one set of self-made vacuum-pressure circulation system (including vacuum pressure tank, vacuum pump, air compressor and tubes). 


\section{Four-point bending performance test method}

The static bending performance of CLT is tested by four-point bending method according to the North American standard ANSI APA PRG320-2012. The specimen span is denoted 30 times of the specimen thickness $(3,150 \mathrm{~mm})$. The distance between the two loading points is $1 / 3$ of the span $(1,050 \mathrm{~mm})$. The loading direction is perpendicular to the surface of specimen. The displacement extensometer is vertically fixed to the center of specimen in the span and thickness directions. The loading speed of $4 \mathrm{~mm} \cdot \mathrm{min}^{-1}$. When the load is up to $20 \mathrm{kN}$, the displacement extensometer is removed and the load is continued to observe the failure mode of CLT specimens in the test process until it ultimately destroyed. And record the maximum breaking load value of CLT specimen failure.

According to the North American standard ANSI APA PRG320-2012, Eq. 1 is used to express the relationship between the elastic modulus of CLT and slope of four-point bending load-displacement curve in linear stage (American Society of Testing Materials 2015):

$$
E=\frac{23 \Delta P l^{3}}{108 \Delta y b h^{3}}
$$

where: $E$ is the elastic modulus of CLT (MPa); $\Delta P / \Delta y$ is the slope of load-displacement curve of CLT in linear stage; $l$ is the span of CLT specimen ( $\mathrm{mm}) ; b$ is the width of CLT specimen (mm); $b$ is the thickness of CLT specimen $(\mathrm{mm}) ; P$ is the load $(\mathrm{N})$.

The bending elastic modulus of CLT is obtained by substituting the specimen dimensions parameters and the slope of load-displacement curve of measured CLT at four-point bending linear stage in Eq. 1. In four-point bending test of CLT, the maximum load of bending failure is read from the load-displacement curve (Fig. 3). Eq. 2 shows the relationship between bending strength and maximum breaking load in four-point bending test of CLT:

$$
f_{b}=\frac{P_{\max } l}{b h^{2}}
$$

where: $f_{b}$ is the bending strength of CLT $(\mathrm{MPa}) ; P_{\max }$ is the maximum breaking load of CLT $(\mathrm{N}) ; l$ is the four-point bending test span of CLT $(\mathrm{mm}) ; b$ is the width of CLT specimen (mm); $b$ is the thickness of CLT specimen (mm).

The bending strength of CLT is obtained by substituting the maximum breaking load and specimen dimensions parameters of four-point bending test in Eq. 2 .

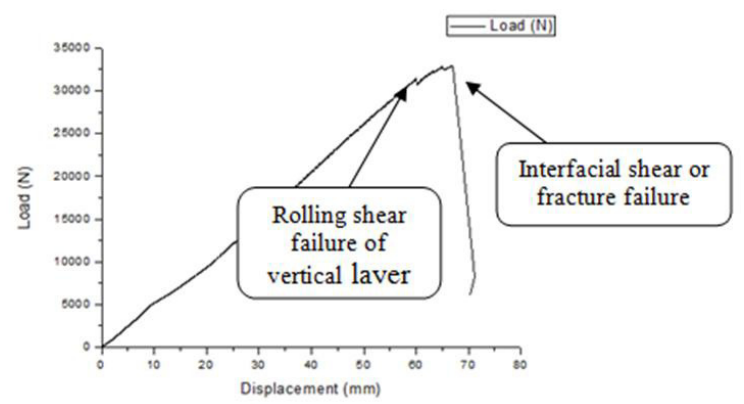

Fig. 3: Load-displacement curve of CLT in four-point bending test. 


\section{Interlaminar shear strength test method of CLT}

The interlaminar shear strength of CLT is tested by short-span three-point bending test method in accordance with the North American Standard ANSI APA PRG320: 2012. The span is 6 times of the thickness $(630 \mathrm{~mm})$ and the width is $305 \mathrm{~mm}$. The loading point is located in the middle of the span, and the loading direction is perpendicular to the specimen surface. During the test, the loading speed is $4 \mathrm{~mm} \cdot \mathrm{min}^{-1}$, and the damage position and failure mode of specimen is observed until the failure of specimen occurs. When the test is completed, the maximum damage load value under interlaminar shear failure is recorded and used for the calculation of interlaminar shear strength of CLT (ASTM D-198: 2015).

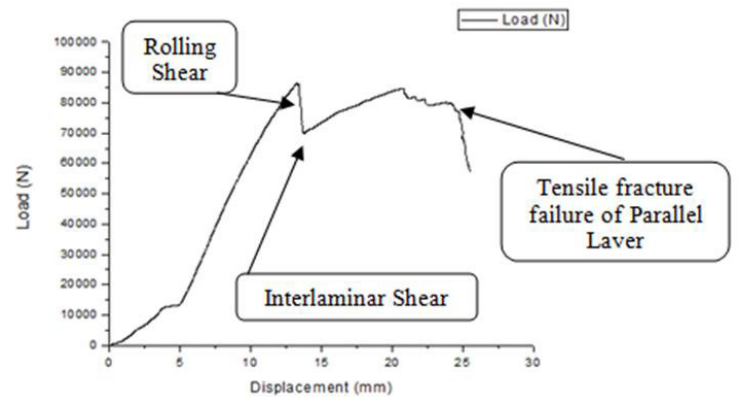

Fig. 4: Load-displacement curve in three-point bending test of CLT.

The damage cause and failure form of specimen are analyzed according to the overall loaddisplacement curve and failure mode. Eq. 3 shows the relationship between the interlaminar shear strength of CLT and the maximum breaking load of interlaminar shear failure during the short-span three-point bending test of CLT (3):

$$
\tau=\frac{3 P_{\max }}{4 b h}
$$

where: $\tau$ is interlaminar shear strength of CLT (MPa); $P_{\max }$ is the maximum breaking load of interlaminar shear failure of CLT $(\mathrm{N}) ; b$ is the width of specimen $(\mathrm{mm}) ; b$ is the thickness of specimen $(\mathrm{mm})$.

The maximum breaking load and dimensions of CLT specimen are substituted into Eq. 3 to calculate interlaminar shear strength of CLT.

\section{Adhesive layer shear strength and wood breaking rate test method}

According to North American standard ANSI APA PRG320-2012, block shear method is used to test the adhesive layer shear strengths and wood failure ratios under dry and vacuumpressure test conditions. Dry test is used to characterize the cementing strength of CLT panel. Vacuum-pressure test is mainly used to characterize the durability and weatherability of CLT glue layer. CLT specimens are processed according to the standard before the test (Wang et al. 2014).

Before the dry test, the specimen is placed in an environment with temperature of $25^{\circ} \mathrm{C}$ and relative humidity of $65 \%$ to adjust to a constant mass state. After that, the adhesive layer shear test is validated. Its loading speed is $10 \mathrm{~mm} \cdot \mathrm{min}^{-1}$.

After the test, the damage load of each adhesive layer is recorded to measure the wood failure area of shear cementation surface. Eq. 4 shows the relationship between the shear strength and shear breaking load of CLT adhesive layer. The wood failure rate is the ratio of wood failure area and total adhesive layer areas: 


$$
f_{v}=\frac{P}{S}
$$

where: $f_{v}$ is the shear strength of adhesive layer of CLT (MPa); $P$ is the breaking load of adhesive layer $(\mathrm{N}) ; S$ is the shear area of adhesive layer $\left(\mathrm{mm}^{2}\right)$.

The shear breaking load of adhesive layer is substituted into Eq. 4 to calculate the shear strength value and wood failure rate of CLT adhesive layer. The shear strength value of a single specimen is the average shear strength of adhesive layers.

\section{RESULTS AND DISCUSSION}

Compared with the main research results of other authors, on the one hand, this study is based on a two-story hemlock orthographic glulam (CLT) demonstration building as the research object, and the unit structure design of CLT; And the production process of CLT hemlock CLT is briefly described, and the test and analysis of its mechanical properties such as elastic modulus, flexural strength, and shear strength and interlayer shear strength of the CLT board in the main strength direction are carried out. Comprehensive and systematic. On the other hand, in the test results and analysis of the bending performance of CLT, the typical bending failure mode of Hemlock CLT was analyzed in detail; and according to the load and displacement curve of the entire test process, it was found that during the bending stress of CLT, it reached After the inelastic deformation phase, the specimen first experienced rolling shear failure in the vertical layer, and then gradually expanded to the interface layer. The ultimate failure mode was shear failure in the interface layer or tensile failure in the parallel layer. Shear strength between the CLT layers in the test results and analysis, under the conditions of the short span three-point bending test, the CLT interlaminar shear performance has a certain correlation with the performance of the CLT parallel layer sawn timber. In the analysis, compared with the dry condition, after the vacuum-pressure impregnation treatment of CLT, the shear strength of the glue layer decreased by $40.77 \%$, and the wood breakage rate of the cemented surface only decreased by $11.69 \%$. The shear strength of the specimen's adhesive layer is mainly determined by the orthotropic properties of the wood. The test results of the CLT adhesive layer's shear strength and wood breakage rate have certain variability. In addition, defects such as wood decay and knots will have a greater impact on the shear performance and durability of the CLT adhesive layer.

\section{Test results and discussion of bending performance of CLT}

Due to the anisotropy of timber, shear strength perpendicular to grain of timber is weaker than bending strength parallel to grain. For structural characteristics of CLT orthogonal assembly, the vertical layer of CLT between lower support and upper pressure head is sheared during bending resistance process, which easily leads to the rolling shear failure of vertical layer. Through the observation and analysis of the test process, the rolling shear failure of vertical layer firstly emerges during the bending resistance process of CLT (Fig. 5a). 


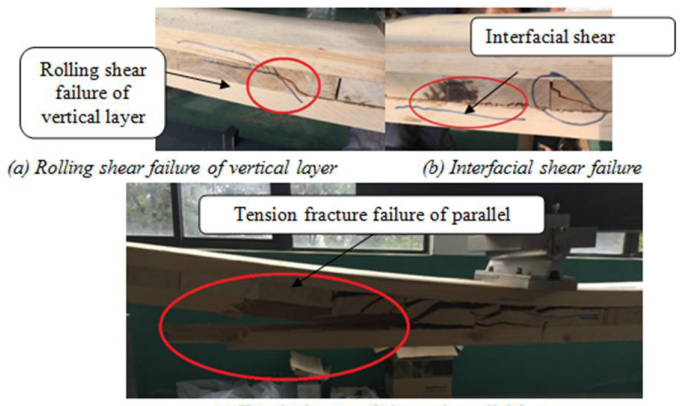

(c) Tensile fracture failure of parallel layer

Fig. 5: Typical bending failure mode of hemlock CLT.

With the increase of load, the rolling shear failure accelerates to extend to the interface layer, resulting in shear failure of interface layer. The interlayer shear failure of CLT also occurs between the upper pressure head and lower support (Fig. 5b). The load applied to CLT specimen is very close to the maximum breaking load in the interfacial shear failure process. When the maximum breaking load is reached, the specimen will be damaged by the tensile fracture of the parallel layer, resulting in the failure of specimen (Fig. 5c).

Fig. 4 shows the load-displacement curve of the whole test process. In the bending resistance process, the CLT test specimen firstly has rolling shear failure of vertical layer while reaching the non-elastic deformation phase. After that, the damage gradually extends to the interface layer. The failure mode is shear failure of interface layer or tensile failure of parallel layer.

According to the test results of CLT four-point bending specimens are analyzed to obtain the elastic modulus and flexural strength in the main strength direction of CLT (Gagnon et al. 2012). The grade 1 CLT four-point bending test results: the average value of $P \max$ is $43.49 \mathrm{kN}$, the coefficient of variation is $8.61 \%$; the average value of $\mathrm{E}_{0}$ is $11966 \mathrm{MPa}$, the coefficient of variation is $3.64 \%$; the average value of $f_{0}$ is $41.51 \mathrm{MPa}$, and the variation is The coefficient is $6.46 \%$. The grade 2 CLT four-point bending test results: average Pmax is $36.87 \mathrm{kN}$, coefficient of variation is $8.21 \%$; average $E_{0}$ is $10668 \mathrm{MPa}$, coefficient of variation is $5.78 \%$; average $f_{0}$ is 34.78 MPa, the coefficient of variation is $6.28 \%$.

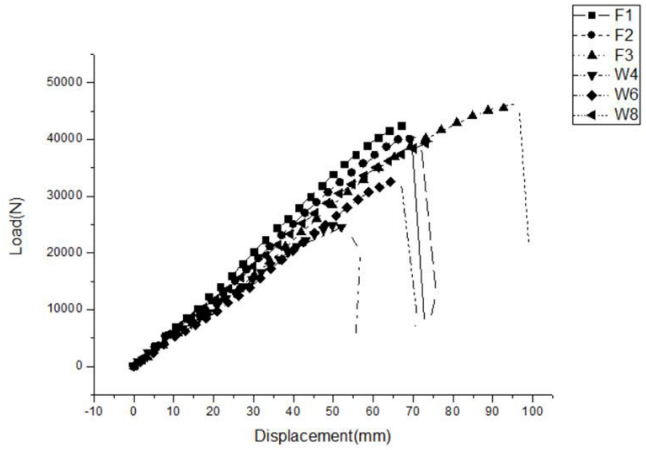

Fig. 6: Compared load-displacement curves of four-point bending test.

Fig. 6 show that the average elastic modulus in the principal strength direction of CLT at Grade 1 is $11,966 \mathrm{MPa}$; the average bending strength is $41.5 \mathrm{MPa}$. For CLT at Grade 2, the 
average elastic modulus in principal strength direction is $10,668 \mathrm{MPa}$; the average bending strength is $34.78 \mathrm{MPa}$. The CLT at Grade 1 has higher breaking load and elastic modulus than CLT at Grade 2. Therefore, the bending performance of CLT can be effectively controlled by grading the parallel-layered substrate during CLT manufacturing. In Sikora et al. (2016) from National University of Ireland tested the bending strength of three-layer Sitka spruce CLT with a unit thickness of $40 \mathrm{~mm}$. Results show that the average elastic modulus in main strength direction is 9,798 MPa; the bending strength is $25.1 \mathrm{MPa}$ (Sikora et al. 2016). In Zhou Jianhui et al. (2016) from Canadian UNB tested the elastic modulus in main strength direction of threelayer Sitka spruce CLT with a unit thickness of $40 \mathrm{~mm}$. The test result is 10,010 MPa. Test results of these two scholars are compared with the our data. It is found that the CLT manufactured in this study has better bending mechanical property than the Sitka spruce and spruce CLT with similar unit structures.

\section{Test results and discussion of interlaminar shear strength of CLT}

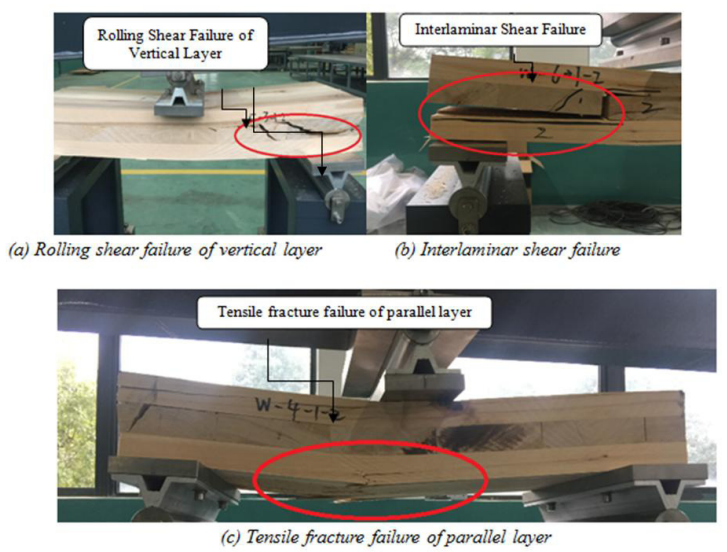

Fig. 7: Short-span three-point bending test failure mode of CLT.

Due to short test span, the three-point bending specimen is greatly affected by shear stress, thus the rolling shear failure occurs first in the vertical layer (Fig. 7a). As test load continues to increase, the rolling shear in vertical layer constantly intensifies, extending to the adhesive interface layer (Fan et al. 2015). Then the shear failure of interface layer occurs (Fig. 7b). When the interlaminar shear failure occurs, most of the specimens have reached the maximum breaking load. After that, the load continues to increase. When the deflection reaches the maximum value, the tensile fracture failure occurs in the parallel layer (Fig. 7c). Fig. 6 shows the load-displacement curve and the failure of specimen when a certain load is reached.

During the test process, the position of interlaminar shear failures is concentrated near support points of specimens and the position is generally located at the interface between parallel and vertical layers, inclining to the parallel ones. In three-point bending test, a downward load $\mathrm{P}$ is applied to the specimen at mid-span load point. Then, each support seats generate upward distribution constraint reactions on the specimen, forming the upward resultant. The specimen is virtually cut in the inner edge near the support seat to take out a small section on the right side of the specimen. The small section is subjected to a pair of equivalent forces in opposite direction near the support point, thus forming shear deformation. 
According to reciprocal theorem of shear stress, the shear stress appears in pairs on the mutually perpendicular sections. Therefore, if there exists shear stress at the interface of beam cross-section, the equivalent shear stress must exist along the longitudinal plane. When the shear stress reaches the shear strength of laminated timber, then there is failure surface along the longitudinal direction. The deviation direction of failure surface is relevant to the shear modulus and strength of longitudinal and transverse laminated timbers. In the test, most of the pseudo-failure surfaces occur near the longitudinal laminar interface. Therefore, the test result is consistent with the theoretical analysis.

The test results of CLT specimens are analyzed to obtain the interlaminar shear strength $\tau$ of CLT in main strength direction. The test results of the interlaminar shear strength of the grade 1 CLT in the main strength direction: the average value of Pmax was $93.95 \mathrm{kN}$ and the coefficient of variation was $8.50 \%$; the average value of $\tau$ was $1.88 \mathrm{MPa}$ and the coefficient of variation was $8.57 \%$.

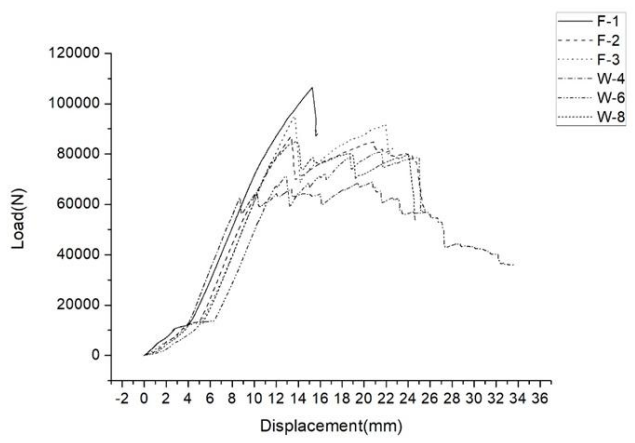

Fig. 8: Compared load-displacement curves of interlaminar shear test.

From Fig. 8, it is known that the average interlaminar shear strength of CLT at Grade 1 is 2.23 MPa. For CLT at Grade 2, the average interlaminar shear strength is $1.88 \mathrm{MPa}$. The former is obviously higher than the latter. The CLT at Grade 1 has higher breaking load than CLT at Grade 2. Therefore, the interlaminar shear performance is relevant to the converted timber performance of parallel layer CLT under the short-span three-point bending test conditions.

\section{Test results and discussion of adhesive layer shear strength and wood failure rate of CLT}

The failure of the bonding surface is observed and analyzed after performing the adhesive layer shear test of CLT under dry and vacuum-pressure conditions (Fig. 9). Fig. 9 shows the failure of No. 1 adhesive layer of No. 1, 2 and 3 specimens under dry test conditions.

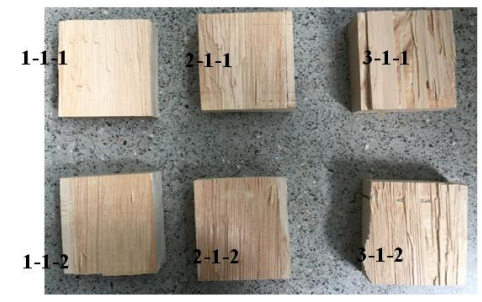

Fig. 9: Adhesive layer shear failure of CLT specimen. 


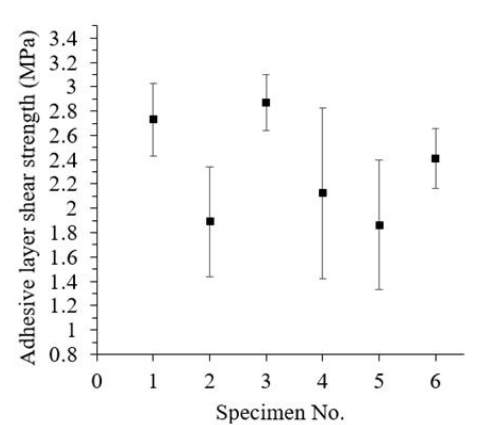

(a)

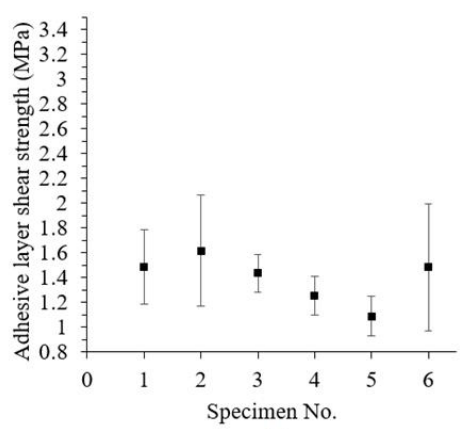

(b)

Fig. 10: Test results of adhesive layer shear strength of CLT: (a) CLT at dry state, (b) CLT at vacuumpressure state.

The above test results show that after dry condition treatment, the average adhesive layer shear strength of hemlock CLT is $2.33 \mathrm{MPa}$ and the average wood failure rate is $86.63 \%$. After vacuum-pressure treatment, the adhesive layer shear strength of hemlock CLT is $1.38 \mathrm{MPa}$ and the average wood failure rate is $76.61 \%$. Compared with the dry condition, the adhesive layer shear strength of CLT decreases by $40.77 \%$ after vacuum-pressure impregnation treatment while the adhesive layer wood failure rate decreases by $11.69 \%$. It can be seen from the test results of hemlock CLT that the adhesive layer shear strength of specimen is mainly determined by wood properties.

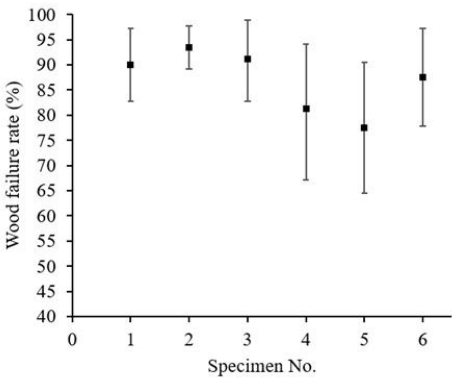

(a)

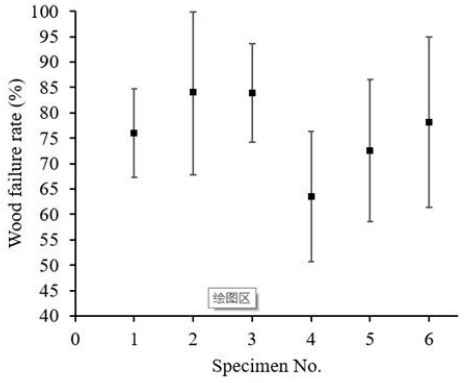

(b)

Fig. 11: Test results of wood failure ratio of CLT: (a) CLT at dry state, (b) CLT at vacuum-pressure state.

Fig. 10 and 11 show that there is a certain variability in the test results of adhesive layer shear strength and wood failure rate of CLT, which is mainly determined by the orthotropy of wood. In addition, it is found that defects such as wood decay and knot have a great influence on the adhesive layer shear property and durability of CLT. Therefore, using the wood with such defects as substrate should be avoided in the CLT processing and manufacturing. 


\section{CONCLUSIONS}

The main conclusions of this study are reflected as follows: (1) The test values of bending and shear performance of Hemlock CLT can meet the relevant grade requirements of Standard ANSI APA PRG320-2012. During the bending process, the CLT specimen firstly exhibits arolling shear failure of vertical layer after reaching the non-elastic deformation phase. After that, the damage extends gradually to the interface layer. The final failure mode is shear failure of interface layer or tensile failure of parallel layer. (2) The interlaminar shear performance is partly relevant to the converted timber performance of parallel layer of CLT under the short-span three-point bending test conditions. The position of interlaminar shear failures is concentrated near support points of specimens and the position is generally located at the interface between parallel and vertical layers, inclining to the parallel ones. CLT at Grade 1 has significantly higher interlaminar shear strength than CLT at Grade 2. (3) In the shear test of Hemlock CLT rubber layer, the vacuum-pressure impregnation treatment method has more influence on the mechanical properties of the wood near the cemented surface than the rubber layer; the weather resistance of the one-component PUR adhesive conforms to the outdoor environment requirements. There is a certain variability in the test results of adhesive layer shear strength and wood failure rate of CLT, which is mainly determined by the orthotropy of wood. (4) The overall mechanical properties of the hemlock specification material and the hemlock CLT can meet the relevant grade requirements of Standard ANSI APA PRG320-2012. The western Canadian hemlock can be used to manufacture engineering CLT plates.

\section{ACKNOWLEDGMENTS}

This study was funded by Co-Innovation Center of Efficient Processing and Utilization of Forest Resources (Nanjing Forestry University, Nanjing 210037, China).

\section{REFERENCES}

1. ANSI/APA PRG 320-2012, 2012: Standard for performance-rated cross-laminated timber.

2. ASTM D-198-2015, 2015: Standard test methods of static tests of lumber in structural sizes.

3. Brandner, R., 2018: Cross laminated timber (CLT) in compression perpendicular to plane: testing, properties, design and recommendations for harmonizing design provisions for structural timber products. Engineering Structures, 171: 944-960

4. Cao, Y., Wang, Y.L., Wang, Z., Wang, J.H., 2016: Application and research progress of overseas cross-laminated timber (CLT) construction. China Forest Products Industry 13(12): 3-7.

5. CSA O112.9-10, 2010: Evaluation of adhesives for structural wood products (exterior exposure).

6. CSA O86-14., 2014: Engineering design in wood.

7. Dugmore, M., Nocetti, M., Brunetti, M., Naghizadeh, Z., Wessels, C. B., 2019: Bonding quality of cross-laminated timber: evaluation of test methods on eucalyptus grandis panels. Construction and Building Materials 211: 217-227.

8. Fan, Q.S., Ying, Y.J., Tang, J.L., 2015: Material mechanics. Tsinghua University Press. Beijing, China. Pp 79-85. 
9. Follesa, M., Fragiacomo, M., 2018: Force-based seismic design of mixed clt/light-frame buildings. Engineering Structures 168: 628-642.

10. Gagnon, S., Bilek, E.M., 2012: CLT Handbook: Cross-laminated Timber. Crosslaminated Timber.FP Innovation, New York, USA. Pp 14-19.

11. GB 50005-2017, 2017: Code for design of timber structures. Beijing, China.

12. Haitao, L., Gang, W., Zhenhua, X., Ileana, C., Xiaohong, X., Huizhong, Z., Zhenyu, Qiu., 2019: Length and orientation direction effect on static bending properties of laminated Moso bamboo. European Journal of Wood and Wood Products 77(4): 547-557.

13. Haitao, L., Huizhong, Z., Zhenyu, Q. Jingwen, S., Dongdong, W., Rodolfo, L., Conggan, Y., Hongzheng, L., Chungui, Z., 2020: Mechanical properties and stress strain relationship models for bamboo scrimber. Journal of Renewable Materials 8(1): 13-27.

14. Lu, Y., Xie, W.B., Wang, Z., 2018: Shear stress and interlaminar shear strength tests of cross-laminated timber beams. BioResources 13(3): 5343-5359.

15. Luengo, E., Hermoso, E., Carlos Cabrero, J., Arriaga, F., 2017: Bonding strength test method assessment for cross-laminated timber derived stressed-skin panels (CLT SSP). Materials and structures 50(4): 1-12.

16. Minmin, L., Wenbo, X., Xiwei, W., Yu, C., Zheng, W., 2018a: Parameters optimization for ultrahigh-pressure pure water and abrasive water jet of Pterocarpus macarocarpus Kurz processing. Wood Research 63(5): 783-794.

17. Minmin, L., Yu, C., Zheng, W., Yunlu, W., 2018b: Optimization and analysis of processing parameters of wooden crafts based on ultra-high pressure water cutting method. Wood Research 63(1): 117-125.

18. Sikora, K. S., Mcpolin, D., Harte, A.M., 2016: Effects of the thickness of cross-laminated timber (CLT) panels made from irishsitka spruce on mechanical performance in bending and shear. Construction and Building Materials 116: 141-150.

19. Sung-Jun, P., Young, J.G., 2018: Load sharing and weakest lamina effects on the compressive resistance of cross-laminated timber under in-plane loading. Journal of Wood Science 64: 538-220.

20. Wang, J. B., Wei, P., Gao, Z., Dai, C., 2018: The evaluation of panel bond quality and durability of hem-fir cross-laminated timber (CLT). Holz als Roh- und Werkstoff 76(2): 833-841.

21. Wang, Y.L., Wang, Z., Wang, J.H., 2017: Research progress of the new generation of heavy CLT wood structure building technology. Journal of Northwest Forestry University 32(2): 286-293.

22. Wang, Z., Lu, Y., Xie, W.B., Gao, Z.Z., Ding, Y.W., Fu, H.Y., 2019: Shear stress analysis interlayer shear strength test of cross laminated timber (CLT) Beam. Scientia Silvae Sinicae 55(2): 157-164.

23. Wang, Z.H., Gao, Z.Z., Wang, Y.L., Cao, Y., 2015: A new dynamic testing method for elastic. Shear modulus and poisson's ratio of concrete. Construction \& Building Materials 100: 129-135.

24. Wang, Z.H., Wang, Z., Wang, J.H., 2014: Dynamic testing and evaluation of modulus of elasticity (MOE) of SPF dimension lumber. BioResources 9(3): 3869-3882.

25. Wenbo, X., Yao, L., Zheng, W., Xiwei, W., Xiaoli, W., Zizhen, G., 2019: Feasibility of predictive assessment of bending performance of CLT plates of Canadian hemlock. Bioresources 14(3): 6047-6059. 
26. Xiaojun, Y., Lan, M., Qi, Z., Yihao, Y., Xiaolan, T., Daoyuan, T., 2018: Enduring performance of self-tapping scew connection in wood members and WPC members. Wood Research 63(5): 833-842.

27. Zhou, J.H., Chui, Y.H., Gerhard, S., 2016: Elastic constants of cross laminated timber panels of industrial size: non-destructive measurement and verification. World Conference on Timber Engineering. Vienna Austria, Pp 2-3.

Wenbo Xie,Yewei Ding, Zheng Wang*, Zizhen Gao, Tongyue Zhang, Yuhao Zhou, Yuhang He

Nanjing Forestry University

College of Materials Science and Engineering

NANJing, JiANGSU

China

*Corresponding author: wangzheng63258@163.com

Xiuling Huang

Nanjing Forestry University

College of Mechanical and Electronic Engineering Nanjing, Jiangsu

China 
